\title{
Mallasohran sadon ja laadun rakentuminen - jyvän valkuaispitoisuuden hallinta?
}

Ari Rajala ja Pirjo Peltonen-Sainio

MTT Kasvinviljely31600 Jokioinen, ari.rajala@mtt.fi, pirjo.peltonen-sainio@mtt.fi

\begin{abstract}
Johdanto
Viime vuosina on tiedotusvälineissä ollut valitettavan usein uutisia liian korkeista mallasohran vakuaispitoisuuksista. Mallastomoiden hyväksymisrajat ohraerän valkuaispitoisuudelle vaihtelevat hieman vuosittain, mutta asetetusta maksimirajasta on jouduttu joustamaan kotimaisen raaka-aineen saatavuuden takaamiseksi. Valkuaispitoisuuden noustessa, panimossa maltaasta saatava uutesaanto laskee ja vierteen ja oluen vaahtoutumisessa ja kirkkaudessa ilmenee epäedullisia muutoksia. Nämä tekijät luonnollisestikin vähentävät tällaisen maltaan ostohalukkuutta. Liian korkea valkuaispitoisuus mallasohrassa on merkittävä ongelma kotimaisille mallastomoille, joiden tuotannosta menee noin kaksikolmasosaa ulkomaiseen vientiin. Sadon laatu ja määrä rakentuvat kasvuolojen ja -tekijöiden vaikutuksesta lajikkeen perimän määräämissä rajoissa, mutta eivät aina yhteneväisesti. Tässä esitelmässä pohditaan virallisen lajikekoetoiminnan tuottaman aineiston ja meneillään olevien mallasohrahankkeiden tulosten pohjalta mallasohran sadon rakentumista sekä sadon ja laadun välisiä kytköksiä ja kasvutekijöiden vaikutuksia niihin.
\end{abstract}

\section{Materiaalit ja menetelmät}

Esitelmä pohjautuu Maa- ja elintarviketalouden tutkimuskekuksen (MTT) virallisen lajikekotoiminnan tuottamaan aineistoon, rajautuen vuosien 1990-2001 koetuloksiin (Kangas ym., 2003) sekä kahden meneillään olevan mallasohrahankkeen tuloksiin (MMM:n rahoittama MALLASKILPA ja TEKES:in rahoittama METAMATU).

\section{Sadon rakentuminen}

Jyvälukumäärä dominoi sadontuottoa

Viljakasvien jyväsato rakentuu seuraavien satokomponenttien määrääminä

oras lukumäärä $\mathrm{m}^{-2} \mathrm{X}$ tähkällisten versojen lukumäärä $\mathrm{m}^{-2} \mathrm{X}$ jyvälukumäärä tähkässä $\longrightarrow$ jyvälukumäärä $\mathrm{m}^{-2} \mathrm{X}$ yksittäisen jyvän paino $=\mathrm{SATO}$

Kun tarkastellaan yksittäisten satokomponenttien merkitystä sadon rakentumiselle, niin voimakkain satoa määräävä tekijä on jyvälukumäärä neliöllä. Tämä käy selvästi esille tarkasteltaessa kaksitahoisten ohralajikkeiden sadon ja jyvälukumäärän yhteyttä (Kuva 1). Jyvälukumäärän vaihtelu selittää tässä varsin laajassa aineistossa $86 \%$ sadossa ilmenneestä vaihtelusta Mikäli tätä yhteyttä tarkastellaan vain yhdellä lajikkeella on kytkös vieläkin voimakkaampi. Yksittäisen jyvän painolla, tai kuten asia usein toisin ilmaistaan, tuhannenjyvänpainolla (TJP), ei näytä olevan virallisten lajikekokeiden aineiston perusteella kovin merkittävää vaikutusta satoon. Jyväpaino selitti sadon vaihtelusta vain noin $8 \%$.

Neliöllä oleva jyvälukumäärä rakentuu tähkien lukumäärään neliöllä ja tähkässä olevaan keskimääräiseen jyvälukumäärään. Kaksitahoisella ohralla maksimijyvälukumäärä tähkässä harvoin ylittää kasvuoloissamme 21-22 jyvää. Tämän rajoittuneen tähkän jyvälukumäärän johdosta jyvälukumäärä neliöllä määräytyy pitkälti tähkälukumäärän mukaan. Tasainen ja voimakas orastuminen höystettynä sopivasti täydentävällä versonnalla mahdollistaa nopeasti maanpeittävän kasvuston muodostumisen ja luo edellytykset runsaalle tähkälukumäärälle ja sitä kautta sadolle.

Vaikka suora kytkös sadon ja jyväpainon välillä onkin heikohko, määräytyy satotaso kuitenkin jyväkoon ja jyvälukumäärän mukaan Kuvan 2 tapaan. Sadon käyttölaatua (mallastus) ajatellen, tietty satotaso tulisi mielummin saavuttaa kohtuullisen korkealla jyväpainolla ja alhaisemmalla jyvälukumäärällä kuin korkealla jyvälukumäärällä ja alhaisella jyväpainolla, jolloin sadon mallastus- 


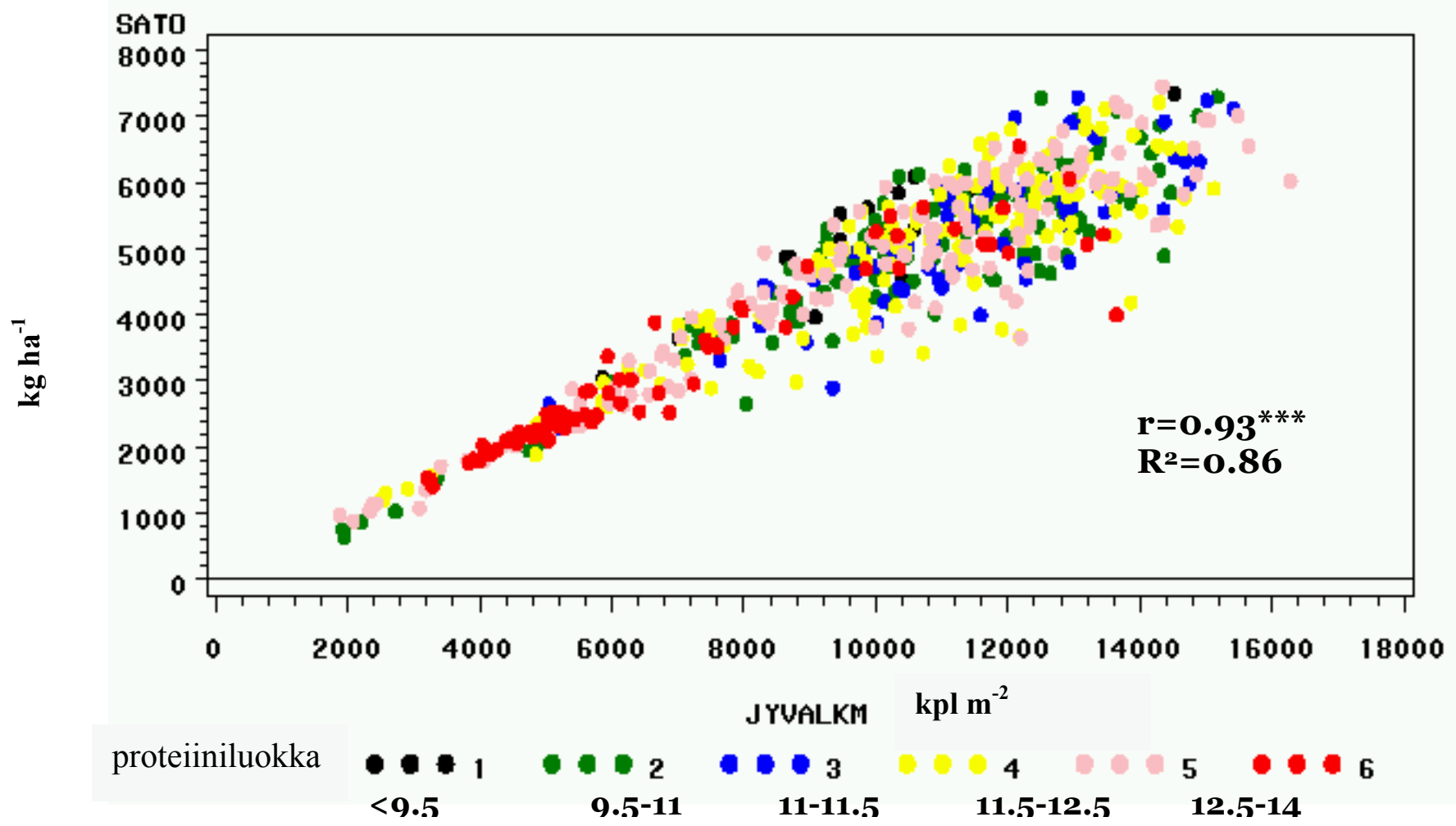

Kuva 1. Kaksitahoisen ohran sadon $\left(\mathrm{kg} \mathrm{ha}^{-1}\right)$ ja jyvälukumäärän $\left(\mathrm{kpl} \mathrm{m}^{-2}\right)$ yhteys. Pisteiden värit ilmentävät sadon valkuaispitoisuutta. Lähde: Viralliset lajikekokeet 1990-2001 (n=603).

kelpoisuus vaarantuu. Lohdullista kyllä jyväkoko ja jyvälukumäärä eivät korreloi negatiivisesti keskenään (Kuva 2). Runsaan sadon tuottava korkea jyvälukumäärä on mahdollista saavuttaa yhdistyneenä painavaan jyvään.

\section{Valkuaispitoisuuden kytkeytyminen satoon ja kasvutekijöihin}

Virallisen lajikekoeaineiston perusteella kaksitahoisen ohran sadon ja valkuaispitoisuuden välillä ilmenee negatiivinen korrelaatio. Valitettavasti vain tämä korrelaatio on varsin heikko, satotason selittäessä vain noin $10 \%$ sadon valkuaispitoisuuden muutoksista. Tämän perusteella, kasvuolojen ja tekijöiden suosiessa sadonmuodostusta valkuaispitoisuus periaatteessa laskee. Tämä käy ilmi myös tarkasteltaesa Kuvaa 1. Korkeilla jyvälukumäärillä onnistutaan suhteellisesti useammin tuottamaan mallaskelpoista raaka-ainetta verrattuna alhaisiin jyvälukumääriin.

\section{Sato-ja proteiinivaste - kasvutekijöiden vaikutus}

Tyypillisesti viljojen sato- ja proteiinivasteet kulkevat hieman toisistaan poiketen. Lähdettäessä alhaiselta kasvutekijöiden tasolta, esimerkkinä alhainen maan ravinnepitoisuus, kasviravinteiden lisäys yleensä nostaa satotasoa, mutta laskee proteiinitasoa. Kasviravinteiden määrää edelleen lisättäessä sadon lisäksi myös proteiinipitoisuus lähtee nousemaan. Saavutettaessa sato maksimin, kasviravinteiden lisäys nostaa enää proteiinipitoisuutta.

\section{Kasviravinteet}

Edellä kuvatun ilmiön kaltainen koejärjestely kahtena kasvukautena peräkkäin täsmälleen samassa paikassa samalaisin lannotuspanoksin (Kemira Kotkaniemi) tuotti erilaiset sato- ja proteiinivasteet (Kuva 3). Jo lähtötasoltaan vuonna 2003 proteiinipitoisuus oli korkeammalla tasolla kuin vuonna 2002. Myöskin vuonna 2002, satovaste tasaantui suuremmilla kasviravinnepitoisuuksilla ja proteiini- 


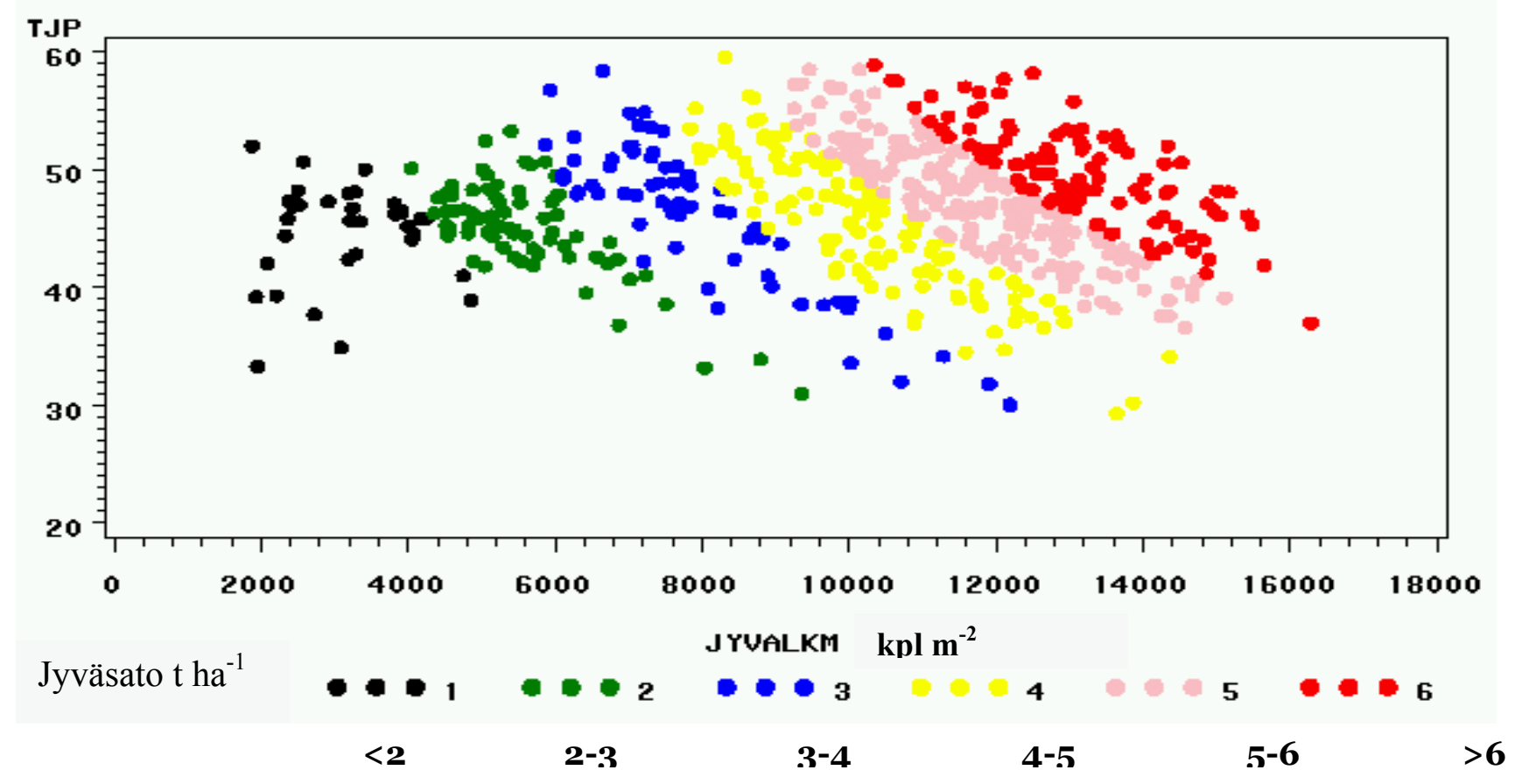

Kuva 2. Tuhannenjyvänpainon (g) (TJP), neliöllä olevan jyvälukumäärän $\left(\mathrm{kpl} \mathrm{m}^{-2}\right)$ ja sadon $\left(\mathrm{t} \mathrm{ha} \mathrm{h}^{-1}\right)$ välinen yhteys. Pisteiden värit ilmentävät sadon määrää. Lähde: Viralliset lajikekokeet 1990-2001 (n=603).

pitoisuus nousi selvästi verrattuna vuoden 2002 tuloksiin (Kuva 3). Mille tasolle valkuaispitoisuus asettuu, rippuu kasvutekijöiden (mm. lohkon viljavuus, siemenen laatu, säätekijät, rikka- ja tautipaine) määräämästä satovasteen suuruudesta. Mikäli ohrakasvustolla on käytettävissään ylenmäärin kasviravinteita, varsinkin typpeä (lannoitus + maasta vapautuva typpi) sadontuottokykyyn nähden, on valkuaispitoisuuden nousu yli hylkäysrajan hyvin ilmeinen riski (Kuva 1).

\section{Aikaisempien vuosien sato- ja proteiinihistorian hyödyntäminen}

Suunnitellessaan mallasohralohkon lannoitusmäärää viljelijällä on edessään aina epävarmuus tulevan kasvukauden sääoloista. Kokenut, lohkonsa kasvukunnon tunteva viljelijä, voi kuitenkin osaltaan vähentää kasvukauden aikaisia epävarmuustekijöitä, peilaamalla lohkon aikaisempien vuosien sato- ja proteiinihistoriaa käytettyihin lannoitemääriin ja suhteuttamalla suunnittelemansa lannoitus realistisille satotavoitteille sen sijaan, että lähtisi tavoittelemaan maksimisatoa. Mikäli lohkon proteiinipitoisuudet, maltillisesta lannoituksesta huolimatta, ovat toistuvasti ylittäneet mallasohran hyväksymisrajan, lienee järkevää käyttää lohkoa johonkin muuhun kuin mallasohran tuotantoon.

\section{Sadanta ja lohkon vesitalous}

Typpitalouden lisäksi toinen merkittävä tekijä sadon määrän ja sen valkuaispitoisuuden määräytymisessä on sadanta ja lohkolla kasvien käytettävissä olevan veden määrä (Rantanen 2000). Hetkellinenkin kuivuus rajoittaa kasvua ja ravinteiden tehokasta ottoa. Suomessa esiintyy sadannan vajausta tyypillisesti touko-kesäkuussa. Sadon- ja laadunmuodostuksen kannalta mallasohran tulisi ottaa valtaosa kasviravinteista ennen tähkälletuloa. Mikäli kasvusto kärsii vedenpuutteesta alkukasvukaudella sadon rakentumisen aikaan, jää kasvusto helposti jälkeen sadontuottokyvyltään optimaalisesta kasvustorakenteesta. Lisäksi tälläisessä tilanteessa myös ravinteiden tehokas otto häiriintyy ja maahan jää kasville käyttökelpoisia ravinteita. Myöhemmin kasvukaudelle sattuvat sateet mahdollistavat taas ravinteiden oton ja tässä vaiheessa otettu typpi kulkeutuu melko väistämättä jyvään ja aiheuttaa proteiinipitoisuuden nousun. Näin varsinkin jos kasvuston ja sadon rakentuminen on häiriintynyt ja muodostunut jyvälukumäärä jää alhaiseksi ravinnepanostukseen nähden. Tällöin 


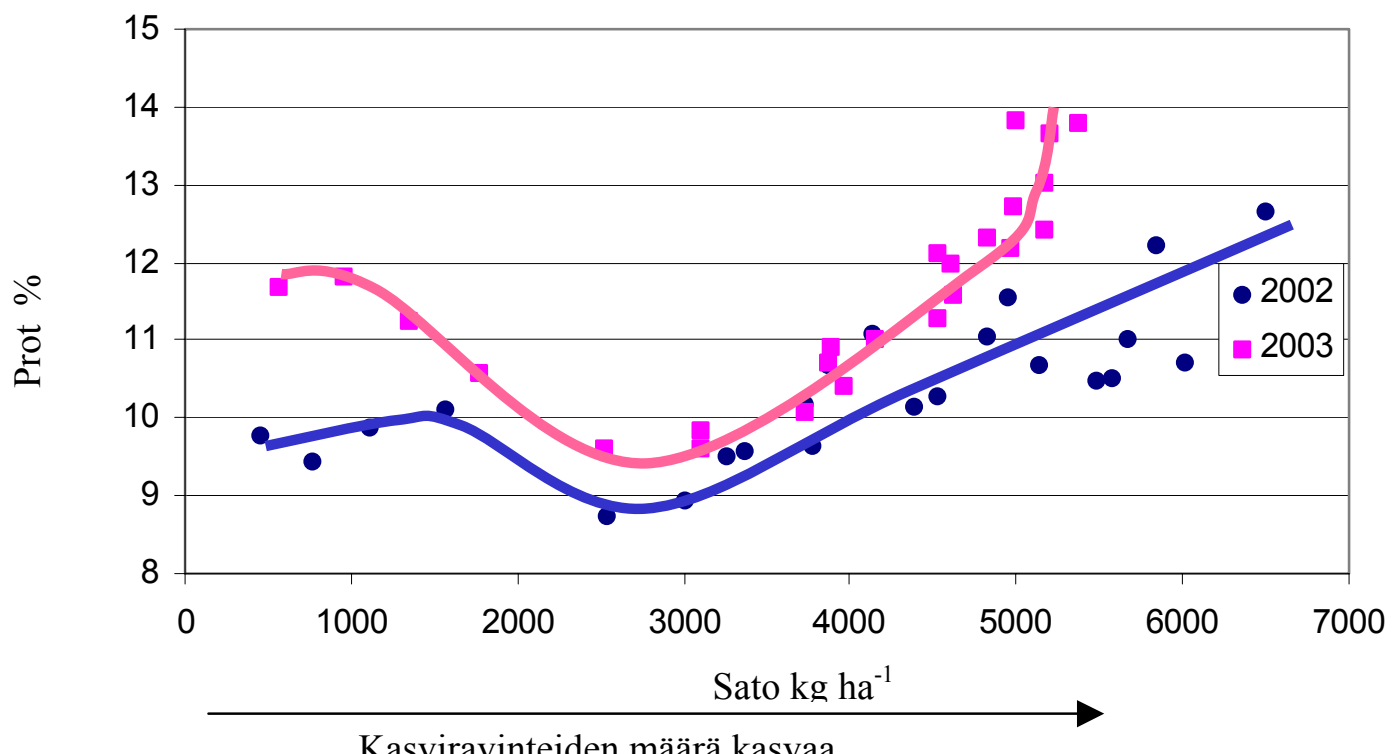

Kuva 3. Saana-lajikkeen sato- ja proteiinivasteet kasviravinnepanostuksen kasvaessa. Lähde: METAMATUaineisto 2002-2003.

ravinteita on ylimäärin täyttyvää jyvää kohden ja jyvän proteiinipitoisuus nousee helposti yli mallasohran hyväksymisrajojen (Kuva 1).

Koska sadannan määrää ja ajankohtaa ei voi säätää, on mallasohralohkon valinnassa kiinnitettävä huomiota lohkon vesitalouden toimivuuteen, eli lähinnä hikevyyteen. Mikäli epävarmuus sadannan riittävyydestä ja sen mukanaan tuomista ongelmista halutaan kokonaan välttää, lienee sadetus ainoa vaihtoehto. Tällä hetkellä sadetuksen käyttö on kuitenkin varsin vähäistä, vaikka periaatteessa vesialueiden sijainti ja veden saatavuus mahdollistaisivat varsin suurenkin peltopintaalan sadetuksen (Pajula ja Triipponen 2003). Sadetuksen avulla voitaisiin oleellisesti vähentää kuivuudesta aiheutuvia vuosittaisia sato- ja laatuvaihtelua, varsinkin kun sadetuksen taloudellisesta kannattavuudesta on positiivisia laskelmia (http://www.agronet.fi/mallasohra).

\section{Johtopäätelmät}

Jyvälukumäärä dominoi kaksitahoisen ohran sadontuottoa kasvuoloissamme. Edellytykset tasaiselle, voimakkaalle ja nopeasti maanpeittävälle kasvustolle lähtevät liikkeelle onnistuneista lohkovalinnoista, muokkaus- ja kylvötoimenpiteistä ja terveen ja laadukkaan kylvösiemenen käytöstä. Nämä mahdollistavat riittävän jyvälukumäärän muodostumisen runsaan sadon takeeksi. Mikäli viljelmällä on sadetusmahdollisuus, voidaan sadetuksella varmistaa voimakkaan kasvuston muodostuminen ja tehokkaan maan ravinteiden hyväksikäytön ennen jyväntäyttymisvaihetta myös kasvukausina, jolloin sadanta jää riittämättömäksi. Näin vähennetään oleellisesti riskiä ravinteiden, erityisesti typen ohjautumiseen täyttymisvaiheessa oleviin jyviin. Voimistuneen tautipaineen vuoksi, onnistunut yhteyttävää lehtialaa nakertavien lehtilaikkutautien torjunta varmistaa häiriintymättömän ja mahdollisimman tehokkaan jyväntäyttymisen kasvuston tuleentumiseen saakka. Näin pyritään realisoimaan muodostunut satopotentiaali mahdollisimman tarkkaan ja pienentämään riskiä proteiinipitoisuuden noususta yli hyväksymisrajan.

\section{Kirjallisuus}

http://www.agronet.fi/mallasohra

Kangas, A., Laine, A., Niskanen, M., Salo, Y., Vuorinen, M., Jauhiainen, L., Mäkelä, L. 2003. Virallisten lajikekokeiden tulokset 1995 - 2002. MTT:n selvityksiä 29: 235 p.

Pajula, H. \& Triipponen, J.-P. 2003. Selvitys Suomen kastelutilanteesta. Esimerkkialueena Varsinais-Suomi. Suomen Ympäristö 629. 88 p.

Rantanen, O. 2000. Ohrasta Oluen Synty, Käsikirja mallasohran tuottajille, pp 42-44. 